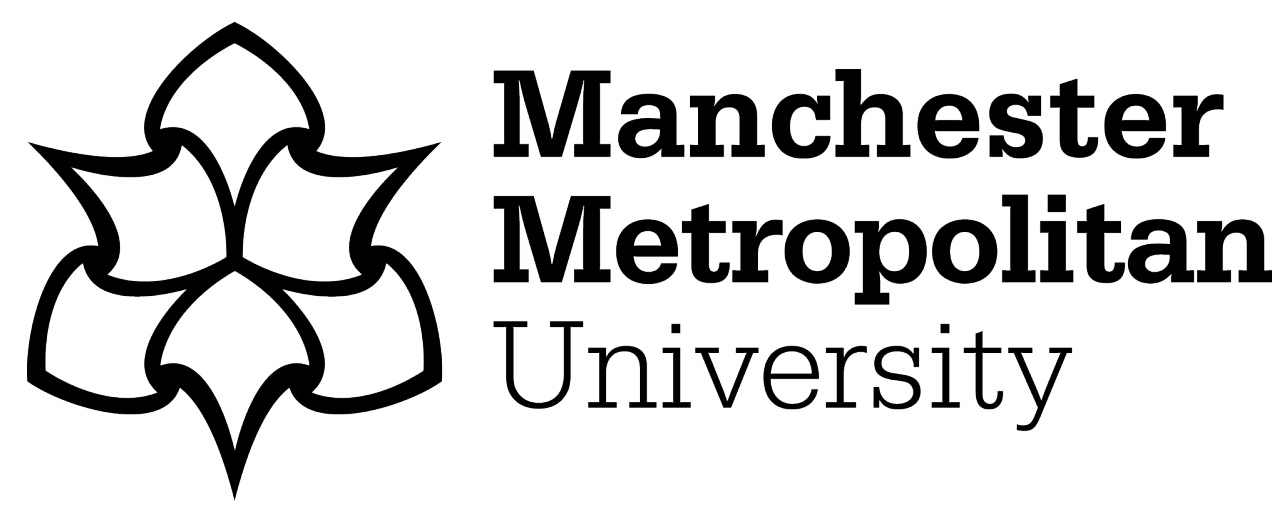

Venkatraman, Prabhuraj D ORCID logoORCID: https://orcid.org/0000-00034290-4510, Scott, Kirsten and Liauw, Christopher (2019) Environmentally friendly and sustainable bark cloth for garment applications: Evaluation of fabric properties and apparel development. Sustainable Materials and Technologies, 23. e00136-e00136.

Downloaded from: https://e-space.mmu.ac.uk/624406/

Version: Accepted Version

Publisher: Elsevier BV

DOI: https://doi.org/10.1016/j.susmat.2019.e00136

Usage rights: Creative Commons: Attribution-Noncommercial-No Derivative Works 4.0

Please cite the published version 


\title{
Environmentally friendly and sustainable bark cloth for garment applications: evaluation of fabric properties and apparel development
}

\author{
P.D. Venkatraman ${ }^{1 *}$, K. Scott ${ }^{2}$ and C.M. Liauw ${ }^{3}$
}

\footnotetext{
${ }^{1}$ Manchester Fashion Institute, Faculty of Arts and Humanities, Manchester Metropolitan University [MMU],

${ }^{2}$ Istituto Marangoni, London E1 6PX and ${ }^{3}$ School of Healthcare Sciences, Faculty of Science and Engineering, MMU, Cavendish Street, Manchester M15 6BG, U.K. *Corresponding author: p.venkatraman@mmu.ac.uk
}

\section{Highlights}

- Ugandan bark cloth recognised by UNESCO is an ideal sustainable material for development of craft-based luxury fashion

- This paper assesses bark cloth for its practical suitability from a technical, processing and manufacturing perspective.

- Interesting surface effects such as dyeing, printing, and laser etching can be made to enhance its aesthetic features

- Strength of bark cloth can be enhanced when fusing with different interfacing by aligning with bark cloth grain direction

- Craft-based garment using Ugandan bark cloth promotes eco-fashion and benefits the community involved in production

\begin{abstract}
Ugandan bark cloth has been recognised by UNESCO as a masterpiece of the 'Intangible Cultural Heritage of Humanity', to protect the knowledge, traditions and livelihoods associated with its production. Bark cloth is a non-woven, fibrous textile that has been produced from the wild fig or mutuba tree (Ficus natalensis) by the Baganda people of southern Uganda for hundreds of years. A typical bark cloth has a rich, terracotta colour and is worn by kings and chiefs during coronations, religious ceremonies and cultural gatherings, as well as for funeral shrouds. Due to the growing awareness and the need to reduce the environmental impact of textiles, there is a pressing rationale to use natural materials or fibres in fashion clothing in recent years as designers and practitioners embrace environmentally sustainable raw materials and promote traditional craftsmanship.
\end{abstract}

Various properties and significance of bark cloth from cultural, ethical, technical and aesthetic perspectives to determine its feasibility as a sustainable fashion textile was explored. The potential of bark cloth specifically in relation to the characteristics of luxury fashion (craftsmanship, quality, rarity, heritage and storytelling), through using techniques that include embroidery, appliqué, gilding, laser cutting, natural dyeing and fusing is highlighted.

The bark cloth was investigated for its practical suitability for apparel end use. Various fabric tests were conducted to determine its performance including fabric drape, stiffness, surface morphology, and tearing strength. The bark cloth was subjected to 
$\mathrm{CO}_{2}$ laser etching and sublimation printing to incorporate surface patterns and attenuated total reflectance Fourier transform infrared spectroscopy [ATR-FTIR] was used to monitor the loss of fibres. Based on the trials, an optimum set of parameters were identified to use laser and sublimation printing. Raw bark cloth was stiff when heat-pressed, so it was fused with various fusible interfacing fabrics [A, B, and C] to enhance drape, texture, handle and strength. Results indicated that bark cloth when fused with woven interfacing [C] improved its strength [warp direction aligned with fabric grain] by approximately six times [330N] the strength of bark cloth [57N]. Fabric drape increased marginally [1.0-3.0\%] when fusing with the interfacing, however it offered better handle when making the garment. A basic test garment (size 12 female full-sleeve top) was developed with the fused bark cloth that offered good drape and its shape and fit were evaluated on a mannequin. Outcomes indicated that bark cloth could be satisfactorily developed into outer garments with specific treatment.

Key words: Bark cloth, sustainable luxury, fabric properties, laser etching and garment fit

\section{Introduction}

Bark cloth is an endangered, non-woven, fibrous textile that has been produced from the wild fig or Mutuba tree (Ficus natalensis), by the Baganda of southern Uganda, since the thirteenth century. It has been designated a masterpiece of the 'Oral and Intangible Cultural Heritage of Humanity' by UNESCO (2008) and remains deeply tied to Baganda identity and tradition (Coombe, 1993, Nakazibwe, 2005, and Musinguzi, 2005). Traditionally used in clothing, bark cloth has historic associations with royalty and status; it is still worn for ceremonial occasions by the Kabaka of Buganda. Historically, the wearing of bark cloth at the royal palace was a sign of position or favour - with subtle variations of style or the addition of skins to denote rank (Nakazibwe, 2005).

Bark cloth making is a highly skilled, gendered craft, passed down through generations of men. It requires careful harvesting of the bark by splitting its outer layer down the length of the tree before gently peeling it off. This activity is performed during the rainy season, when the trees have more sap, the bark is suppler, and the tree is less likely to be damaged by the process (Nakazibwe, 2005). The naked trunk is then wrapped in banana leaves for a few days, which serves to protect the inner bark and prevent dehydration; in this way, the bark may be sustainably harvested every year. Therefore, the processes associated with the harvesting of bark cloth show a consistent respect for and harmony with the local environment and are environmentally friendly. In addition, the bark cloth extracted from F.natalensis grows naturally with no fertilizers.

The bark is steamed or soaked to soften its texture, before being pounded by a series of welldesigned wooden mallets. Through this process, the bark fibre felts, becomes finer, smoother and more pliant and grows in size significantly (Figures 1, 2 and 3). It is then spread out in the sun for the natural, rich red-brown colour to develop that is favoured in the region (Rwawiire, Luggya and Tomkova, 2013 and Rwawiire et al., 2012), although it may be dyed black by 
burying in iron-rich mud. Finishing includes the darning of any small tears in the cloth with raffia and the patching of any larger irregularities, before a final beating (Nakazibwe, 2005).

For centuries, bark cloth was an item of local and regional economic importance, being traded across central and east Africa (Figure 1). However, the introduction of woven textiles, by Swahili-Arab traders in the mid-1800s and later by the British, undermined barkcloth's importance and production (Nakazibwe, 2005, Trowell and Waschmann, 1953). Successive political and economic issues have impacted on the viability of barkcloth production - which was even prohibited in the 1970s and 1980s (Rwawiire and Tomkova, 2014); as a result, the number of expert makers had diminished.

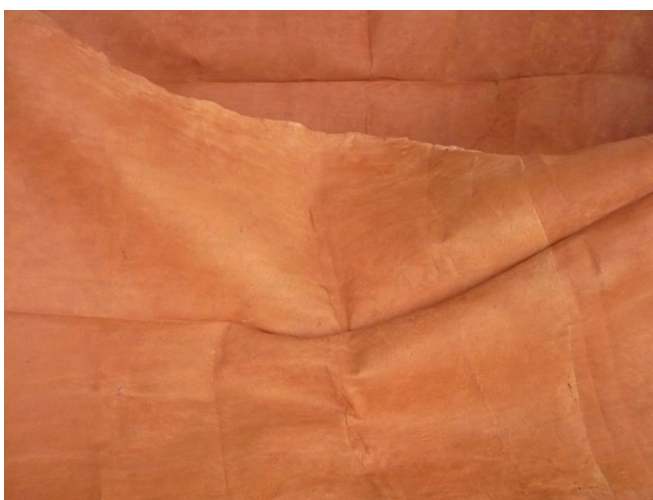

Figure 1. Bark cloth sheet (Scott, 2014) Figure 2. BOTFA visit - 2014 (Scott, 2014)

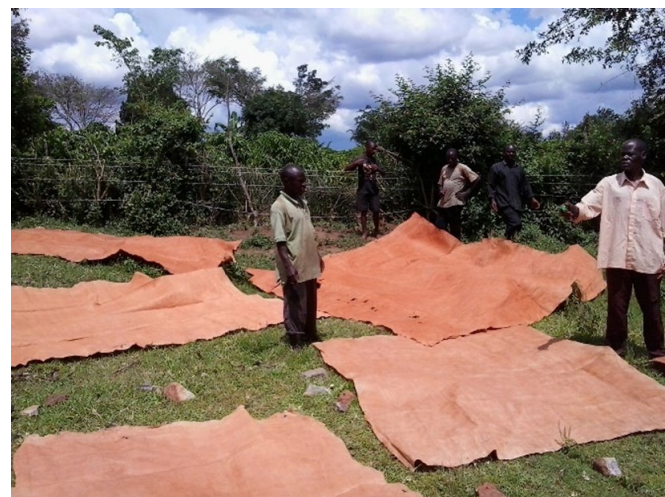

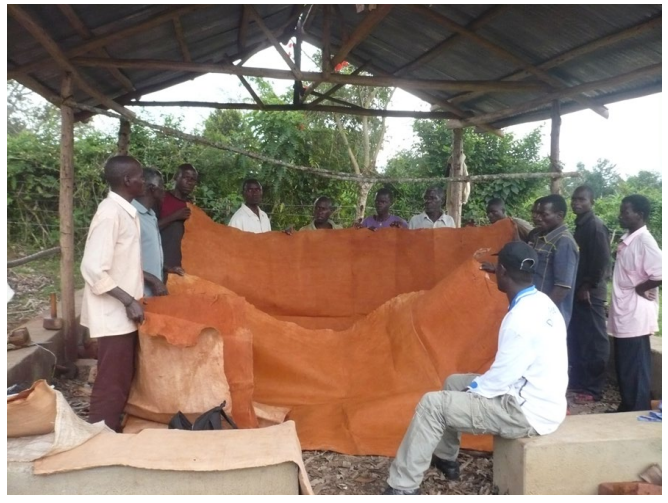

Figure 3. Purchasing bark cloth from BOTFA

(Scott, 2014)

During fieldwork in Uganda in 2014, a bark cloth project at Kibinge, Masaka District was visited (Figures 2 and 3). Through this UNESCO funded initiative, the Bukomansimbi Organic Tree Farmers Association (BOTFA) was working to promote the growth of more wild fig trees and of bark cloth production. An apprenticeship programme enabled ten expert bark cloth makers each to train young apprentices in their craft and to engage in activities to promote its cultural value within the community (UNESCO, 2008). The social and economic benefits to the region have great potential. The local people are proud of their work and ready to engage in more trade, but a sustainable market is needed for their cloth. In addition, its wearability must be improved for contemporary fashion contexts and its ability to adapt to new markets. 
A recent visit to Uganda (August 2019) revealed some new challenges: the apprenticeship programme in Bukomansimbi was suffering from the lack of market for the cloth and, as a result, some young trainees became disillusioned with the slow financial return on their work and left the programme. Two elderly bark cloth makers have died in the last year, adding to the urgency of training new makers. Therefore, the need to increase opportunities and to incentivise bark cloth making is of paramount importance. An impressive vocational training centre is in the process of being built, but funds for its completion have stalled and more investment is needed to ensure ongoing training (Scott, 2019).

Ficus natalensis is increasingly used as part of an informal agroforestry strategy in which the trees provide shade for food crops while adding nutrients to the soil. Ninth generation bark cloth makers Paul Bukenya Katamiira and Vincent Kajooga in Bukomansimbi claim that their families have grown mutuba trees for hundreds of years and that they have always kept their land fertile. Currently in the region, indigenous trees (including F. natalensis) are being cut down for eucalyptus plantations, which are draining the soil of moisture and nutrients and thus negatively impacting crops in surrounding fields. An incentive is needed to plant $F$. natalensis instead of non-indigenous species - to plant trees that fit harmoniously within the local ecosystem and which may provide added value and income generation through the traditional, sustainable craft of bark cloth making. This research does not propose the large-scale commercial growth of trees for bark cloth making, but rather argues for the value of these trees and the cloth that they can yield within the discourse of sustainable textile development that points to alternative ways of sourcing materials (Scott, 2019).

Bark cloth produced through the project is being sold at a Fair Trade price - proposed by the makers - that recognises the amount of work, technical skill and tacit knowledge involved in its production and which is higher than the local living wage (Parker, 2014 and WFTO, 2017). It is sourced in a sustainable way that acknowledges the local context of production and the 'artisan's realities' (Mazzarello et al., 2017: S2947). Makers produce the cloth on their own terms, on their own properties during daylight hours, having full autonomy in how much and when they work; some would prefer to work on longer into the evening sometimes so that they can manage their crops during the day, but cannot do this without access to electricity to power light. A future goal of this project would be to facilitate solar panels for the bark cloth makers and for the vocational training centre at Bukomansimbi.

Adams (2015) and Worden (2016) reported that the meaning of traditional bark cloth, although having become associated with funerals and the wrapping of deceased bodies in the Baganda community, is being transformed in Uganda. Several Ugandan artists and fashion designers currently are using bark cloth, as they rediscover it as a medium for cultural revival and expression and value its sustainability. Ivan Yakuze, Sanaa Gateja, Ronex Ahimbisibwe, Wasswa and Fred Mutebi are artists who are using it in collage, product design and even as canvas; Xenson Znja, Jose Hendo and Gloria Wavamunno have used it in fashion collections (Robertson, 2014, Worden, 2016), (Figure 4). Fred Mutebi is actively involved in encouraging mutuba tree planting and bark cloth production as part of the BOTFA project. 


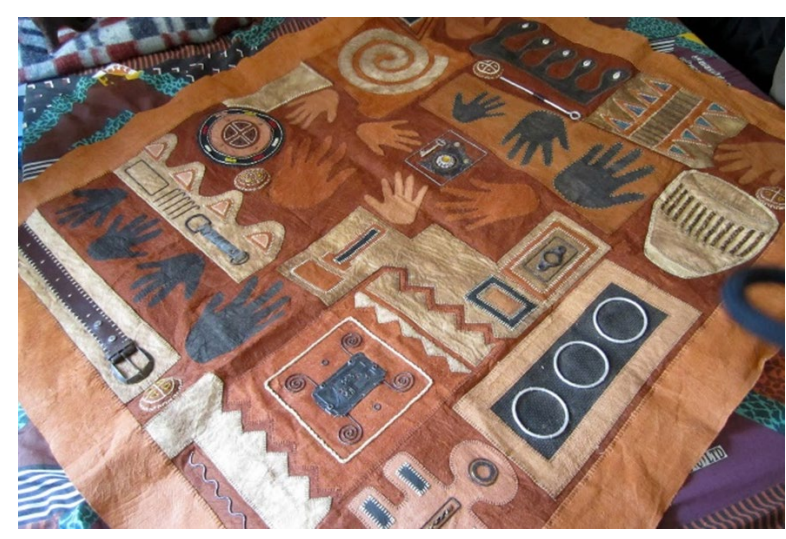

Figure 4. Artwork by Yakuze Ivan

(Courtesy of Lesli Robertson)

John Elkington developed the triple bottom line framework to measure sustainability that includes financial (profit), environmental (planet) and social (people) (Elkington, 1994). Sustainable fashion faces challenges in finding a balance and being responsible in three key areas: social equity, ecologic stability and economic viability (Gwilt, 2014). Development of Ugandan bark cloth related fashion products has a direct influence on the community that brings bark cloth into the global market. A steady increase in its usage will enable more people to engage in its production and should help to preserve the future of this important cultural craft, as the current artisans working to produce bark cloth have a limited market for the cloth. Therefore, a sustainable increase in the use of bark cloth as an eco-fashion textile will help to re-vitalise the Ugandan craft sector, develop trade and employment opportunities and in turn revitalise the local community and economy. This, in effect, could meet the triple bottom line of sustainability principles.

'Bark Cloth Europe' was established in 1999 by a Ugandan-German couple who work with ethically sourced bark cloth to develop textiles that have improved and varied properties for multiple uses, including as a leather substitute for shoes or even for car upholstery, as well as for interior design. They have contributed to the growing awareness of bark cloth overseas, but its potential needs further exploration for fashion garments.

Recently, bark cloth has been evaluated for several technical applications, such as epoxy resin biocomposites for automotive panels (Rwawiire et al., 2015). Researchers (Rwawiire and Tomkova, 2014) also evaluated the thermo-physiological properties and comfort parameters. The paper identified bark cloth's lower thermal absorptivity compared to cotton, which the researchers claimed would have a warm feeling next to the skin. They further concluded that water vapour permeability was higher compared to cotton fabrics. Although previous researchers have identified bark cloth for various uses, this paper focuses on its potential as a fashion fabric and addresses some of the practical - as well as aesthetic - garment making considerations in using bark cloth.

Recently, there have been initiatives by companies such as Marks and Spencer, Patagonia and Nike, to implement sustainable design strategies in apparel design and production processes. In addition, fashion designers and high street clothing have begun to respond more positively 
to environmental and sustainable imperatives throughout the supply chain from the design stage, material selection, manufacture, through to disposal stage (Gwilt, 2014). This involves identifying impact throughout design, production, distribution, consumer use and end of life of the garment. The recently developed life cycle assessment tool (cradle-to-grave approach) enables meaningful assessment of energy consumption, water use, waste produced, and emissions caused during production. The cradle-to-cradle approach attempts to return end of life material into production or to the environment (Gwilt, 2014). Sustainable design strategies (such as, using low impact materials, design for zero waste, minimising transport, easy care, recycling/reuse) can be implemented either during the design stage, whilst in production or for end of life systems, after assessing a typical life cycle of the garment. However, decisions made in this regard should not unduly disrupt other processes within the supply chain (Gwilt, 2014).

Tischner and Charter (2001) identified four approaches for sustainable design - repair, refine, re-design and rethink, with the emphasis on repairing existing products. In order to implement sustainable design strategies in clothing, Niinimäki and Hassi (2011) argued it is necessary to understand consumer needs, values and satisfaction and that systemic change is required for meaningful implementation. This means extending the life of the garment and understanding the intrinsic qualities that have emotional value to the customer. They also added that consumers are willing to support sustainable design strategies (repair a garment; recycle; exchange old for new, etc) during the production and consumption stages. In addition, slow fashion - with local production - and customisation could enhance sustainable garment development (Niinimäki and Hassi, 2011). A product made with high quality, ethical values, including the use of durable and sustainable materials, will extend its lifetime and deepen product satisfaction (Fletcher, 2008). Bark cloth garments certainly satisfy criteria for achievement of these aspects as the story of the bark cloth making in the context of improving Ugandan communities will convey emotional value to the consumer, the latter together with the sustainability of the material will encourage an empathetic relationship between the wearer and garment. WRAP [Waste and Resource Action Programme] (2015) in its guide for sustainable clothing to enhance 'performance' and 'durability' for various product categories reported that if the clothing industry works together on the sustainable clothing lifecycle then it will reduce the environmental footprint of clothing and save around $£ 3$ billion per year from cost of resource used in making and cleaning clothes. Extending the longevity of clothes reduces carbon, water, and waste footprints by $20-30 \%$ each year. It also distinguished between physical durability (resists wear and tear) and emotional durability (one that fits the consumer's taste or relevance).

In 2015, global textiles and clothing consumed 79 billion cubic metres of water, 1715 million tonnes of $\mathrm{CO}_{2}$ emissions and 2 million tonnes of waste (Pulse of Fashion Industry, 2017), and by 2030 the number mentioned above would increase by at least $50 \%$ if the business-as-usual scenario continues. The United Nations World Commission on Environment and Development defined 'sustainability' as the development that meets the needs of the present without compromising the ability of future generations to meet their own needs (WCED, 1987). In recent times the negative environmental impact of clothing and fashion has been highlighted in major reports (Šajn, 2019 and Wolf et al., 2014), which stress the need for use of sustainable 
practices such as enhancing the longevity of clothes, increasing consumer awareness and changing the way that clothes are washed and dried. As clothing and textiles are known for high resource utilization and natural fibres such as cotton require large volumes of water, land and pesticides, there is a need to focus on sustainable fibres and materials.

To reduce the negative impacts of cotton, several natural fibres such as bast fibres - linen, hemp, jute, ramie etc. - were recommended as potential fibre blends with cotton for clothing applications (Debonath, 2017). Clothing processing also consumes large amounts of water and chemicals during finishing and dyeing. New chemicals that are water-free, bio-degradable and reusable were developed recently for fabric finishing that reduce water emissions [include textile and chemical waste] and reduce water consumption and energy use (De Smet et al., 2015). There were several initiatives of circular economy/fashion, where 'repair' and 'reuse' of the resources and recycling of materials were recommended (Muthu, 2019). Other recent developments include the development of ways to identify and predict the environmental impact of textiles by using a software system that also identifies solutions (Resta and Dotti, 2015).

The Higg Index suite of tools was developed by Sustainable Apparel Coalition [SAC] launched in 2011, which is a self-assessment tool that enables manufacturers, retailers, brands and trade associations of all sizes to measure the social and environmental impact at every stage of the process and to identify areas for improvement (Higg Index, 2019). The materials sustainability index [MSI] score accounts for the impact of several stages of materials processing. For instance, the MSI of cotton fabric is 98; viscose/rayon 62; flax 162; polyester 44; nylon 60 and lyocell 57. It is interesting to note that polyester has a low impact compared with other fibre types. MSI considers the various processing stages involved, including the raw material source; method of yarn formation; fabric formation; preparation, colouration and finishing (Higg Index, 2019). [MSI score is based on global warming, eutrophication, water scarcity, resource depletion, fossil fuels used, and chemistry certification]. Compared with similar cellulosebased fibre types, cotton, lyocell and viscose, the impact of bark cloth on the environment is negligible and supports sustainable initiatives. The current database does not feature natural materials. It would be ideal to have natural materials such as bark cloth to be part of the database, as it involves only raw bark harvested from $F$. natalensis tree and sustainable processing without any use of chemicals, machinery and intensive labour.

The above developments were only recent and require time to realize their potential, and much remains to be done to see a noticeable impact. Hence, there is a strong rationale to find ways to be more sustainable especially in the use of raw materials. For instance, the use of environmentally friendly and sustainable materials such as bark cloth in mainstream fashion will certainly reduce the impact on the environment as it can be used without any major finishing or processing.

Unlike other raw materials, F.natalensis grows naturally without the need for fertilizers. Bark cloth has a stiff texture and to enhance the appearance, drape, and stability of the garment, there is a need to fuse it with the interfacing. Traditionally, interfacing (Nagano, 1985) contributes extra body, support, shape retention and increased wearability (Collier et al., 1989). Koenig 
and Kadolph (1989) evaluated a range of interfacing fabrics and reported that it affected the drape and contour of the garment shape. They added that the construction of the interfacing material affected the drape of the main fabric. When using interfacing fabrics, there are a number of factors to be considered, in addition to their sustainability. Collier et al., (1989) studied the effect of interfacing on the shear and drape behavior of apparel fabrics. They reported for woven interfacings three factors affect composite fabric stiffness: density, the stiffness ratio of the main fabric and interfacing, and the stiffening effect of adhesives. Fabric and garment drape have been widely studied for woven and knitted fabric structure. Süle (2012) reported that the bending rigidity of the woven fabric increased with thick weft yarns and weft yarn densities and when warp yarn tension is increased. In addition, the drape coefficient of woven fabrics increased when the weft yarn density and weft yarn thickness were increased. These researches demonstrated the influence of interfacing in drape and rigidity of the fabric.

\section{Methods}

This research has assessed bark cloth for its practical suitability for fashion clothing, from both technical, processing / manufacturing and aesthetic standpoints.

Due to the natural origin of bark cloth, its structure is not uniform, its texture is coarse and fibre strands are irregular as it has thick and thin areas. It is relatively rigid, can have a creased appearance, possesses low strength and is hydrophilic in nature. Hence, in order to determine its practical suitability for apparel end use, several standard textile parameters were assessed including fabric thickness [BS 5084], area density, bulk density, fabric drape [BS 5058], flexural rigidity [BS 9073-7: 1998], tearing strength [BS EN 13937-3:2000], tensile strength [BS EN ISO 13934-1: 2013], bursting strength [BS EN ISO: 13938:2 1999].

Prior to fabric testing, all fabrics were conditioned in standard laboratory conditions $20 \pm 2^{\circ} \mathrm{C}$ and relative humidity $65 \%$ for $24 \mathrm{hrs}$. The fabric was fused with interfacing for 12 seconds, at $162^{\circ} \mathrm{C}$ and $500 \mathrm{~kg}$ pressure was applied to ensure the fabric is conducive to wear. To determine a suitable fusing interface, woven, knitted fusible interfacings were trialled. Bark cloth was also etched to produce surface designs that can be embedded, and several laser parameters were tested to identify an optimum laser engraving parameter. Laser etching was chosen to develop intricate design patterns on its surface and to enhance the aesthetic appearance of bark cloth. The process is also environmentally friendly as no chemicals/washing stages are involved and, when implemented properly, does not compromise the quality and strength of the base fabric (Venkatraman and Liauw, 2019). A study of laser etching of denim (Venkatraman and Liauw, 2019) has shown that high quality faded and patterned effects can be produced on denim; the indigo dye is vapourised from the fibre surface by energy of the laser beam. If the laser parameters are set correctly, the strength and quality of the material is not compromised. Relative to traditional techniques, the method requires reduced labour resource, consumes much less energy and requires no chemicals and water for processing/rinsing, therefore polluting effluents and chemical waste are eliminated.

In addition, a sublimation print design was carried out using Heatjet heat transfer machine, 44 Evol and the design was printed on to heat transfer paper using Epson Sure 
colour F6200 ink jet printer. During the final stage, the fused bark cloth was assembled into a garment and its fit was evaluated on a mannequin.

Three different fusible interfacings were selected, a knitted fusible interfacing (A), a lightweight woven interfacing (B); and a heavy weight woven fusible interfacing (C). Following fusing, the composite fabric was evaluated for its fabric weight, drape, strength and results are presented in Table 1. Fusible interfacing, A is a polyester warp knit fabric $\left(55 \mathrm{~g} / \mathrm{m}^{2}\right.$; thickness $0.25 \mathrm{~mm}$ ) with weft insertion that has a fabric count $13 \times 14$ (wales $/ \mathrm{cm} \times$ courses $/ \mathrm{cm}$ ); $B$ is a cotton woven fabric $\left(59 \mathrm{~g} / \mathrm{m}^{2}\right.$; thickness $\left.0.21 \mathrm{~mm}\right)$ with fabric count $36 \times 23$ (ends/ $/ \mathrm{cm} \mathrm{x}$ picks $/ \mathrm{cm})$ and $\mathrm{C}$ is a cotton woven fabric $\left(112 \mathrm{~g} / \mathrm{m}^{2} ; 0.45 \mathrm{~mm}\right)$ with fabric count $29 \mathrm{x} 22$ (ends/cm x picks/cm).

As explained earlier, bark cloth in its natural form is coarse, rigid, has uneven texture, possessing high fabric drape coefficient, and low strength. At this stage, in order to enhance the durability, drape and stability of the garment three different commercially available interfacings were randomly selected. Fusible interfacings are widely used in garments to enhance the appearance, stability and fabric handle, especially if the main fabric is pliable. The fusible interfacing can be washed at $40^{\circ} \mathrm{C}$ and be pressed at medium heat after fusing. Fusible interfacing $\mathrm{A}$ is a knitted fabric composed of polyester and coated with polyamide. The polyamide resin in powder form is coated on to the fabric. Fusible interfacing B is a lightweight woven cotton fabric coated with a polyamide resin. And fusible interfacing $\mathrm{C}$ is medium weight cotton woven fabric coated with a polyamide resin (Stabler, 2019). When the interfacing is heat pressed or passed through the heated roller the resin melts and sticks to the base fabric. However, after the initial tests with the cotton or polyester interfacing, we will source alternative, sustainable interfacings that align with bark cloth's biodegradable properties.

If bark cloth is fused with an interfacing made of cotton woven fabric, then the latter can be easily removed mechanically for disposing of end of life garments made of bark cloth. Cotton fabric interfacing can be recycled by normal methods, which excludes all the accessories used, for example, buttons or zippers for garment closure; these may be upcycled. As the bark cloth products are made for small volume, eco-fashion niche markets, large end-of-life disposal volumes are not anticipated. However, the research is also attempting to stabilise the texture, handle, strength and water resistance of bark cloth - as well as develop different aesthetic qualities - with natural biopolymers using corn starch, agar or cassava which will be fully compostable.

The surface morphology of the bark cloth was imaged using a Carl Zeiss, Supra 40VP scanning electron microscope (SEM). The backscattered electron detector was used to obtain images of the samples under variable pressure conditions (30 Pa). EDX-Energy dispersive x-ray spectroscopic analysis was performed on Apollo 40SDD EDAX using an acceleration voltage of $20 \mathrm{kV}$ and a working distance of approximately $15 \mathrm{~mm}$. EDX is an analytical technique to determine the elemental composition of materials. The stubs were then loaded into the SEM for imaging and analysis. 
The chemical structure of the bark cloth was investigated using attenuated total internal reflectance Fourier transform infrared spectroscopy (ATR-FTIR). Covalent bonds are excited into various unique vibration modes when irradiated with infrared radiation, each bond therefore has its own vibrational fingerprint (Stuart 2009). The FT-IR spectra for the bark cloth were recorded from $4000 \mathrm{~cm}^{-1}$ to $450 \mathrm{~cm}^{-1}$ using a Thermo-Nicolet 380 FTIR fitted with a Smart iTR single bounce ATR accessory with diamond internal reflection element. Spectra were made up of 32 scans with resolution of $4 \mathrm{~cm}^{-1}$.

Table 1 Physical parameters of bark cloth

\begin{tabular}{|c|c|c|c|c|c|c|c|c|}
\hline & \multirow{2}{*}{$\begin{array}{c}\text { Area } \\
\text { densit } \\
y \\
\left(\mathrm{~g} / \mathrm{m}^{2}\right)\end{array}$} & \multirow[t]{2}{*}{$\begin{array}{c}\text { Thickne } \\
\text { ss } \\
(\mathbf{m m})\end{array}$} & \multirow[t]{2}{*}{$\begin{array}{c}\text { Bulk } \\
\text { density } \\
\left(\mathrm{g} / \mathrm{cm}^{3}\right)\end{array}$} & \multirow[t]{2}{*}{$\begin{array}{c}\text { Drape } \\
\text { coefficien } \\
t(\%)\end{array}$} & \multicolumn{2}{|c|}{$\begin{array}{c}\text { Flexural } \\
\text { rigidity } \\
(\mu \mathrm{Nm})\end{array}$} & $\begin{array}{l}\text { Tearing } \\
\text { strength } \\
\text { (N) }\end{array}$ & \multirow[t]{2}{*}{$\begin{array}{c}\text { Bursting } \\
\text { strength } \\
\text { (kPa) }\end{array}$} \\
\hline & & & & & 㐿 & $\begin{array}{l}\infty \\
0 \\
0 \\
0\end{array}$ & 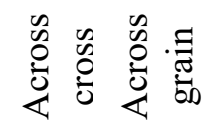 & \\
\hline $\begin{array}{l}\text { Bark } \\
\text { cloth } \\
\text { (BC) }\end{array}$ & 143 & $\begin{array}{c}0.672 \\
(0.05) *\end{array}$ & 0.213 & 94.70 & 127 & 117 & $\begin{array}{cc}2.9 & 2.61 \\
4 & \end{array}$ & NA \\
\hline $\begin{array}{l}\text { BC + } \\
\text { Fusible } \\
\text { interfaci } \\
\text { ng A }\end{array}$ & 201 & $\begin{array}{c}0.87 \\
(0.03)\end{array}$ & 0.231 & 96.2 & 612.3 & 112.6 & NA & $\begin{array}{c}149.2 \\
(10.19) * \\
\text { Distensio } \\
\text { n } 21.6 \\
\text { mm }\end{array}$ \\
\hline $\begin{array}{l}\text { BC + } \\
\text { Fusible } \\
\text { interfaci } \\
\text { ng B }\end{array}$ & 218 & $\begin{array}{c}0.74 \\
(0.05)\end{array}$ & 0.294 & 95.54 & 345.8 & 624 & $\begin{array}{cc}1.6 & 2.45 \\
3 & \end{array}$ & NA \\
\hline $\begin{array}{l}\text { BC + } \\
\text { Fusible } \\
\text { interfaci } \\
\text { ng C }\end{array}$ & 234 & $\begin{array}{c}0.88 \\
(0.06)\end{array}$ & 0.265 & 97.80 & 501 & 318 & $\begin{array}{cc}9.1 & 4.57 \\
5 & \end{array}$ & NA \\
\hline
\end{tabular}

*indicates standard deviation; NA - Not applicable
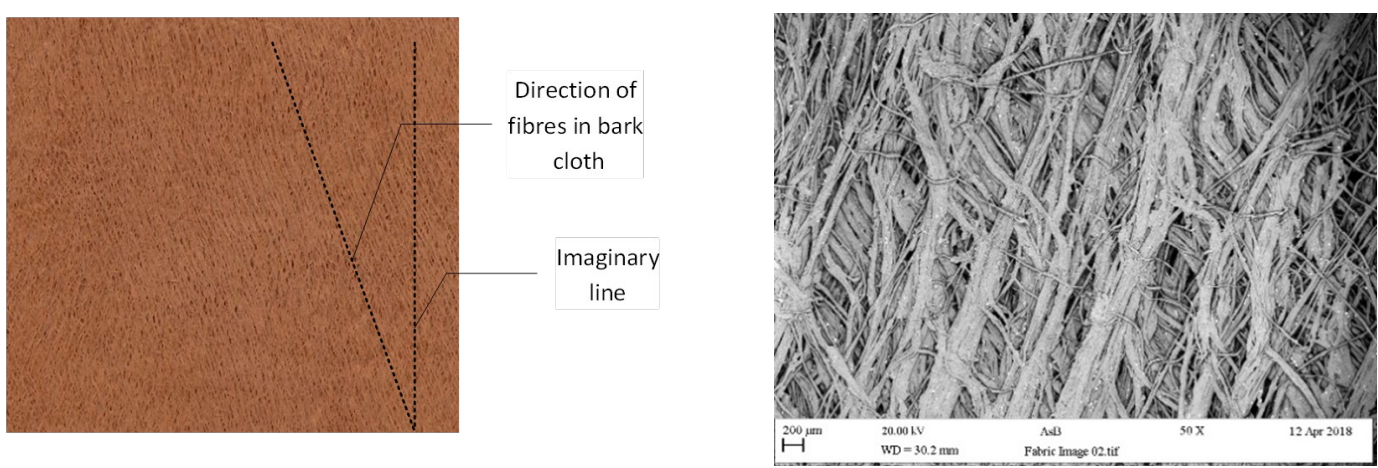

Figure 5. Bark cloth

Figure 6. Fibre alignment in bark cloth 50x 


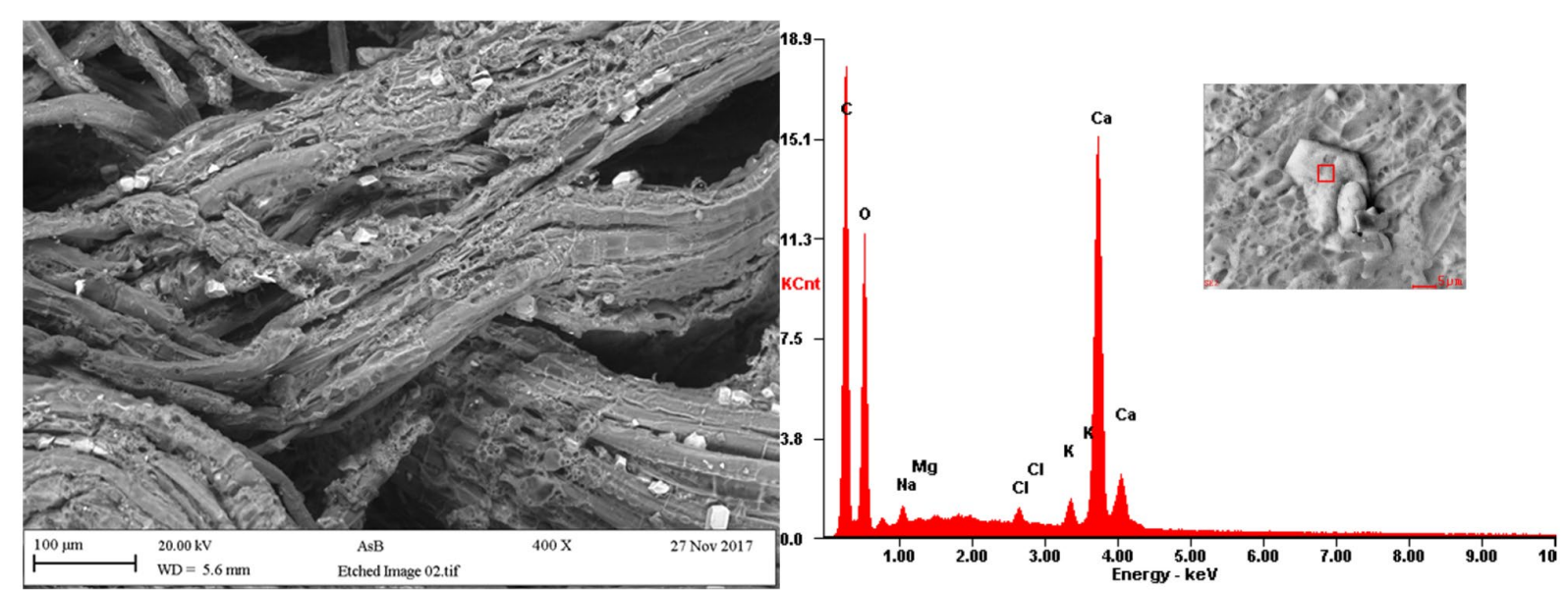

\section{Figure 7. SEM bark cloth - calcium traces on bark cloth - Energy Dispersive spectroscopy (EDX)}

\section{Results and discussions}

Bark cloth had a fabric weight of $143 \mathrm{~g} / \mathrm{m}^{2}$, thickness $0.67 \mathrm{~mm}( \pm 0.05$ S.D) and there were variations due to the natural formation of the bark. Figures 5 and 6 illustrates a typical bark cloth with its characteristic terracotta colour and SEM image (x50 magnification) shows the alignment of fibre strands. A close-up examination of bark cloth revealed white particles (Figure 7) which was examined further using EDX analysis for identifying elements and it revealed that bark cloth had traces of calcium and sodium on its surface. SEM images (Figure 7) revealed that the fabric has a random or criss-cross alignment of fibre strands and it affects the surface thickness. Fabric drape evaluation revealed that the cloth was firm and stiff $(94.7 \%)$ and behaved like paper. Fabric drape is a method of determining multi-directional curvature of a circular specimen and its ability to drape under its own weight (Taylor, 1993 and Saville, 1999). When bark cloth was fused with interfacing, the drape coefficient increased marginally across all the fusible interfacings; however, the fabric handle with knitted interfacing (A) was satisfactory, as the knitted interfacing composite offered flexibility unlike bark cloth which was stiff on its own.

Fabric stiffness was evaluated to understand the resistance to bending on its weight using Shirley stiffness tester. Stiffness is dependent on fabric density, closeness of fibre strands and thickness of the material. The stiffness of the bark cloth was determined in grain and cross direction and it affects how a material drapes over an object/body. Flexural rigidity of the bark cloth was calculated from bending length and mass in gram per square metre. The flexural rigidity of the bark cloth in the grain direction was marginally higher compared to cross direction and this was also noticed was when the bark cloth was fused with interfacing A (knitted fusible) and C (woven fusible). However, in the case of lightweight fusible interfacing (B), the flexural rigidity in the cross direction was higher than in the grain direction. This could be associated to the density of resin that creates an adhesive layer with the bark cloth. The flexural rigidity of the composite fabric fused with interfacing A was lower in the cross direction compared to composite fabrics fused with interfacing $\mathrm{B}$ and $\mathrm{C}$. Hence, this interfacing was selected for garment making. The tearing strength of the bark cloth on its own was negligible, however, when the cloth was fused with the interfacing there were reasonable 
amount of strength. The bursting strength was evaluated for the composite bark cloth with knitted fusible interfacing and it offered reasonable resistance. Its strength was $149.2 \mathrm{kPa}, 21.6$ $\mathrm{mm}$ distension and it ruptured at 8.0 seconds. This result could be comparable to a typical medium weight single jersey fabric.

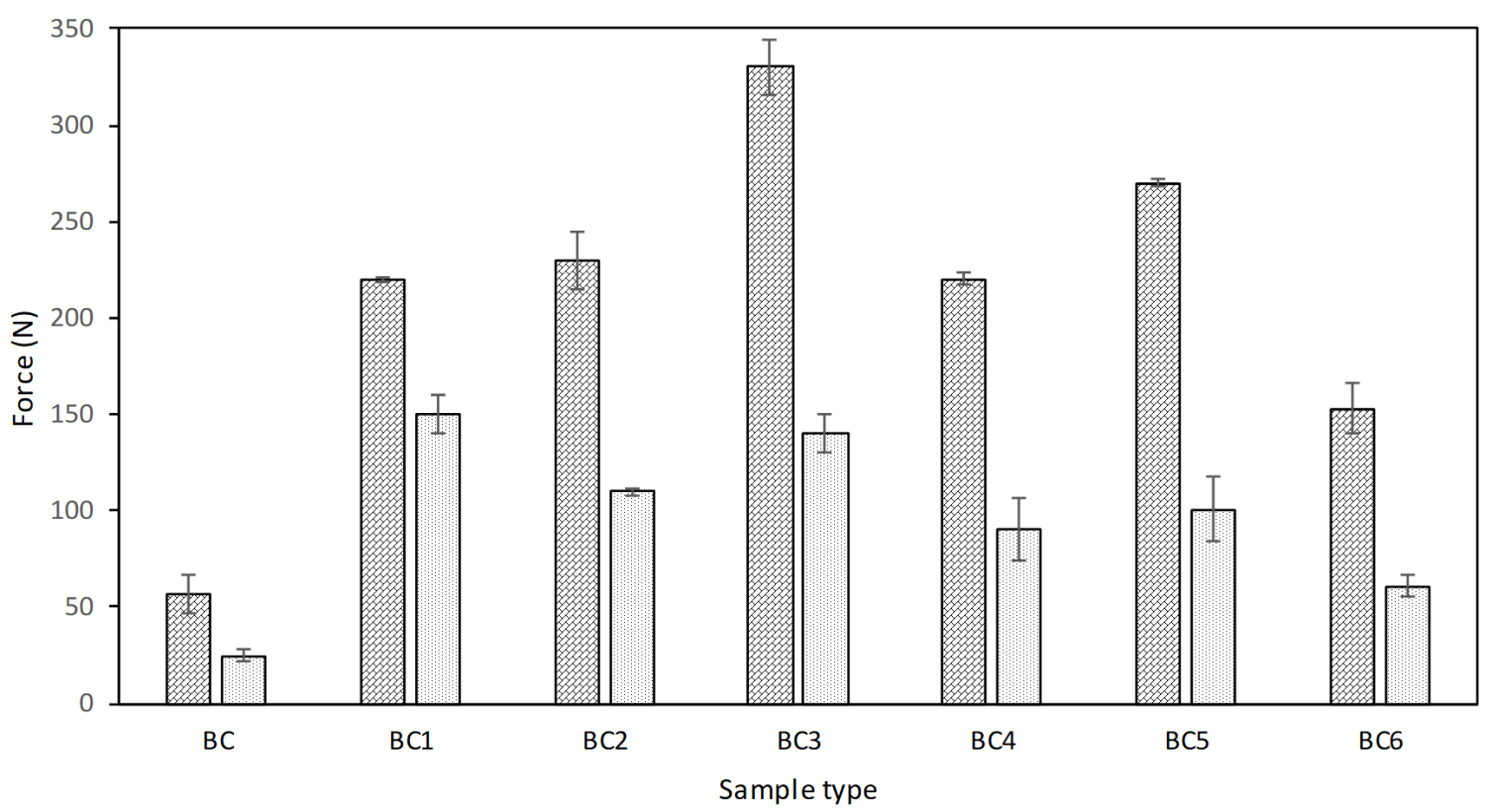

圆 Warp tensile strength $\quad \square$ Weft tensile strength

Figure 8. Bark cloth tensile strength

[BC- bark cloth; $\mathrm{BC} 1$ - bark cloth with interfacing $\mathrm{C}$; $\mathrm{BC} 2$ - bark cloth with interfacing $\mathrm{B}$; $\mathrm{BC} 3$ - bark cloth grain aligned with interfacing $\mathrm{C}$; $\mathrm{BC} 4$ - bark cloth grain aligned with interfacing $\mathrm{B}$; $\mathrm{BC} 5$ Interfacing C; BC6- interfacing B]

It could be noted from the Figure 8, that the bark cloth [BC] possesses low strength in warp and weft directions. Our results show that tensile strength was $57 \mathrm{~N}$ [warp direction] and $25 \mathrm{~N}$ [weft direction] as against previous research $101.7 \mathrm{~N}$ and $23.5 \mathrm{~N}$ in warp and weft respectively (Rwawiire et al., 2014). When bark cloth was fused with heavy weight cotton interfacing [BC1], the tensile strength increased approximately four times the bark cloth strength. It was also quite interesting to note that when the bark cloth grain direction was aligned with the grain direction of interfacing, the tensile strength of fabric composite increased to $330 \mathrm{~N}$ from 220 $\mathrm{N}$ (in the warp direction) with the non-aligned direction [BC1]. It is worth pointing out that the interfacing material [BC5] had a good tensile strength in warp and weft directions. However in the weft direction, the tensile strength improves six times when fused with heavy weight interfacing $[\mathrm{C}]$ in both the cases - fabric grain aligned with the grain direction of bark cloth and non-aligned direction.

In the case of the bark cloth that was fused with light weight interfacing the difference between the fabrics that was aligned and non-aligned directions did not produce any increase in the tensile strength and in fact, it decreased the tensile strength marginally. In the weft direction, the tensile strength was higher in the non-aligned direction compared to fabric grain aligned composite. 
Therefore, it could be inferred that the strength of bark cloth can be enhanced using cotton interfacing particularly with the heavy weight interfacing for those applications that require higher strength. However, the fusing of bark cloth with heavy weight interfacing also increases its stiffness in grain direction. On the other hand, when fusing with light weight fabrics tensile strength improves in both the directions, which also increases the stiffness of the overall bark cloth. Hence, considerable care had to be given when selecting interfacing materials to enhance the strength of the bark cloth.

Although the strength of the bark cloth can be enhanced with interfacing, it is difficult to compare bark cloth with other apparel products, such as denim or jersey, as unlike woven fabric [made of interweaving warp and weft yarns - interlaced at right angles] or knitted fabric (series of interconnected loops made with one or two set of yarns), bark cloth is better described as a nonwoven fabric [fibre web bonded together by thermal or mechanical or other methods without yarn formation]: the fibres criss-cross in largely random directions based on the natural formation of fibres within the tree, the collagen fibres in animal skins (e.g. leather) are also randomly disposed. Given this vast difference in structure, it is highly impractical to replace conventional textiles with bark cloth. However, utilisation of bark cloth is anticipated to be within niche, craft based, eco-fashion that could feature within a couture or demi-couture garment. It is also anticipated that bark cloth can be used alone, without interfacings, in certain carefully considered applications; a throw blanket is an obvious example. As such items will be made of $100 \%$ bark cloth, they will be fully biodegradable at end of life.

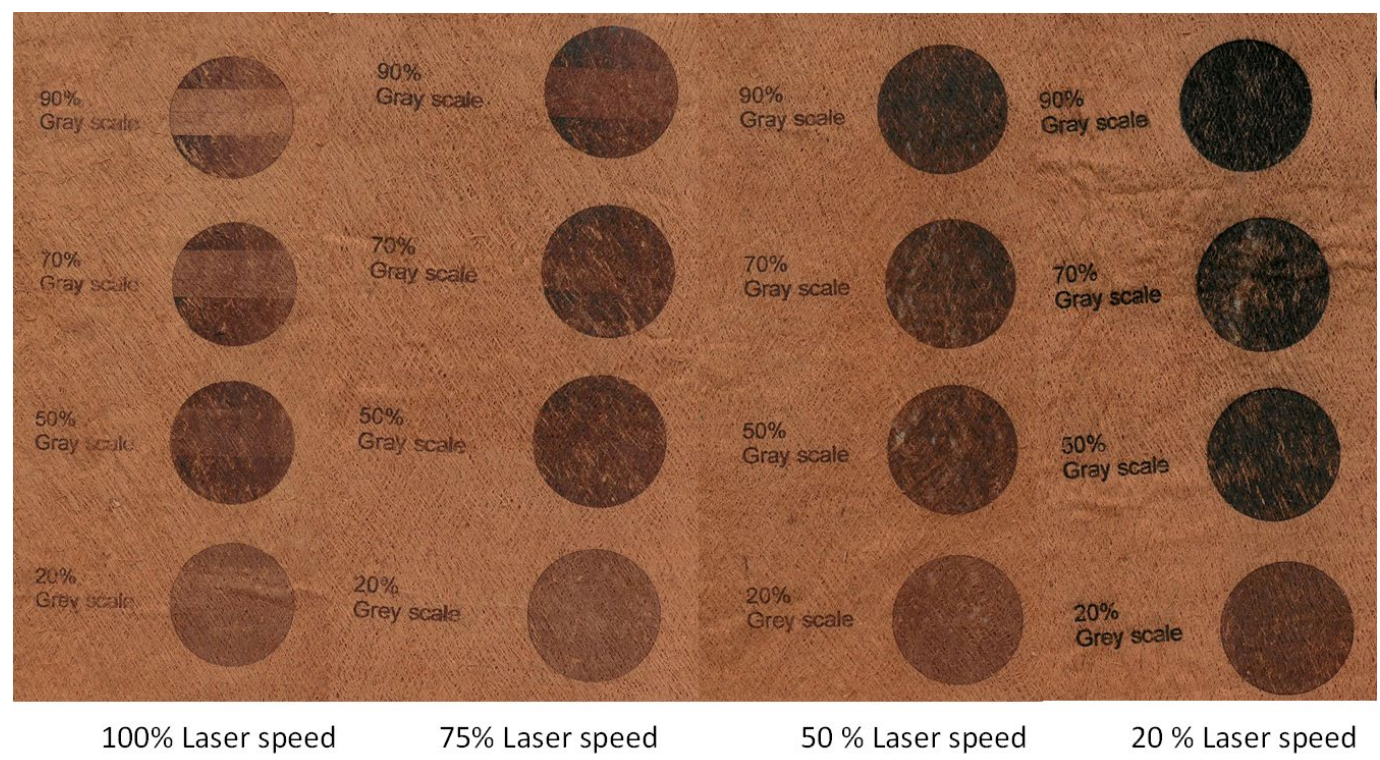

Figure 9. Bark cloth laser etching at $5 \%$ laser power and 500 pulses per inch (PPI) 


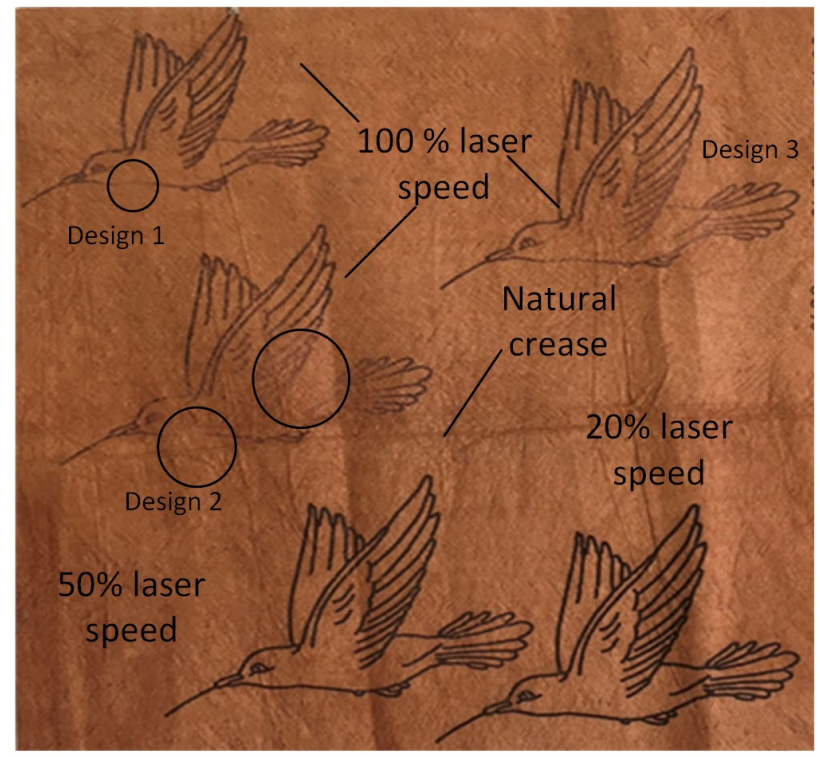

Design 1 - lack of fabric thickness;

Design 2 no etching; Design 3 medium etching

Figure 10 Bark cloth laser engraving - different laser speed 


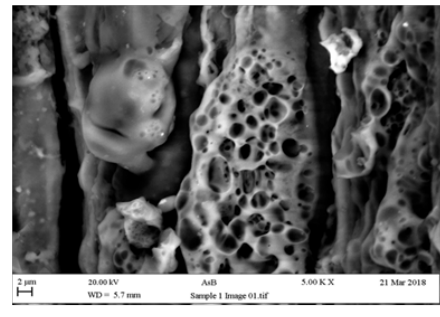

$100 \%$ LS $90 \%$ GS

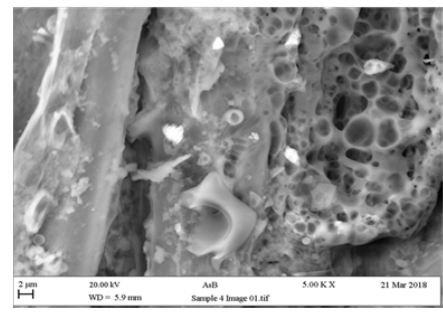

$100 \%$ LS $20 \%$ GS

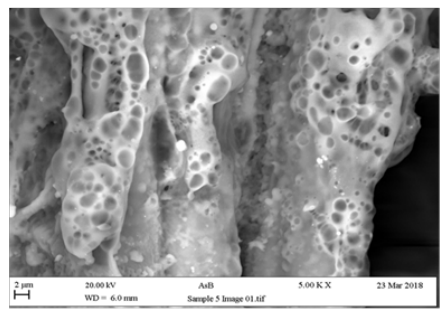

75\% LS 90\% GS

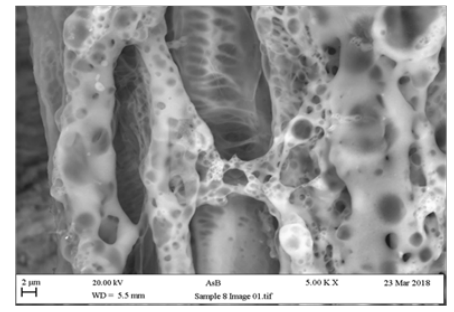

$75 \%$ LS $20 \%$ GS

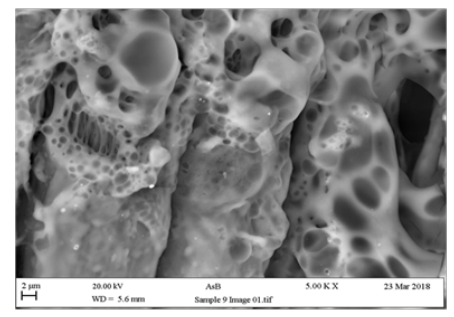

$50 \%$ LS $90 \%$ GS

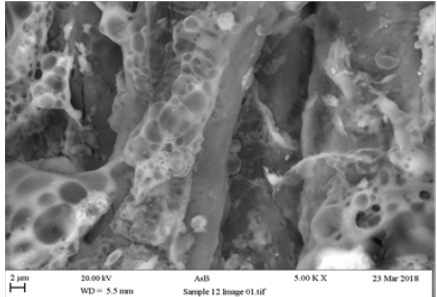

$50 \%$ LS $20 \%$ GS

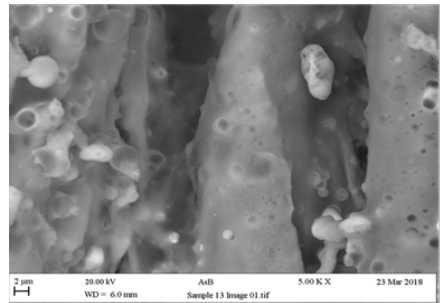

$20 \%$ LS $90 \%$ GS

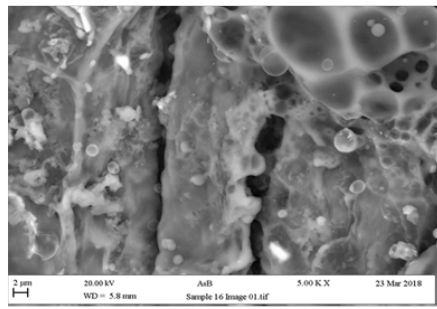

$20 \%$ LS $20 \%$ GS

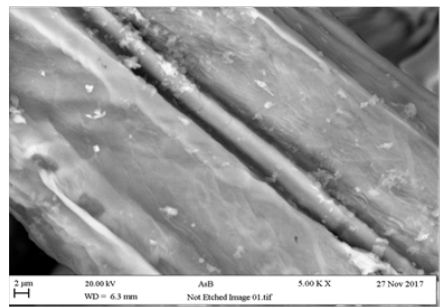

Un etched bark cloth

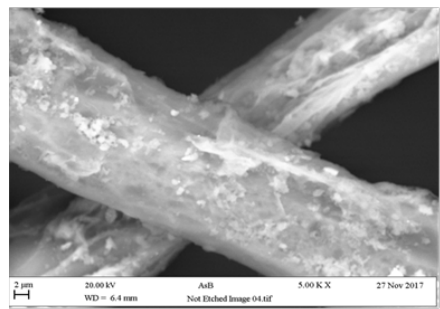

Un etched bark cloth fibre

Figure 11. SEM bark cloth analysis $\mathbf{x 5 0 0 0}$

Laser etching or patterning is a method of creating design on the surface of the bark cloth using $\mathrm{CO}_{2}$ laser. Some of the parameters that were varied were laser speed [100\%, 75\%, 50 and 20\%] and gray scale, GS [90\%, 70\%, 50\%, and 20\%] (Figures 9 and 10). The other parameters including laser power were maintained at $5 \%$ and 500 laser pulses per inch. At $100 \%$ laser speed (5\% Laser Power [LP] and 500 PPI) bark cloth produced less darkening, in other words, thermal degradation was less, and it produced a lighter shade. At 75\% laser speed (5\% LP and $500 \mathrm{PPI})$ the fabric produced a darker shade in the design, where the thermal degradation was comparatively higher than the $100 \%$ laser speed. It can be noted that at $50 \%$ and $20 \%$ LP the 
cloth degradation was higher compared to $70 \%$ and $100 \%$ laser speed. All the fabrics were etched at the lighter side of the cloth after fusing the bark cloth with interfacing. This was because in the darker side of the fabric the thermal degradation was severe as the material was dry.

The SEM images (Figure 11) reveal that at 100\% LP and 90\% GS the amount of surface degradation due to laser etching was evident that removed the surface fibres compared to $100 \%$ LS and 20\% GS. A similar trend was noticed across 75\%, and 50\% laser speed. However, at $20 \%$ laser speed and $20 \%$ gray scale the surface damage was less. It should also be noted, that the laser engraving at 20\% GS and 20\% LS did not affect the entire thickness of the bark cloth. Figure 10 revealed that at $100 \%$ laser speed, the amount of laser etching surface was less compared to $50 \%$ and $20 \%$ laser speed. This was because the laser does not produce a burning effect on the surface fibres; hence, the pattern or design was less visible. In addition, since the bark cloth does not have a uniform surface thickness and texture, the laser etching on the bark cloth was less consistent. However, by fusing the bark cloth with interfacing and reducing the laser speed, patterns had been produced (Figure 9). 50\% and 20\% laser speed produced more thermal degradation compared to $100 \%$ laser speed resulting in darker designs on bark cloth. 


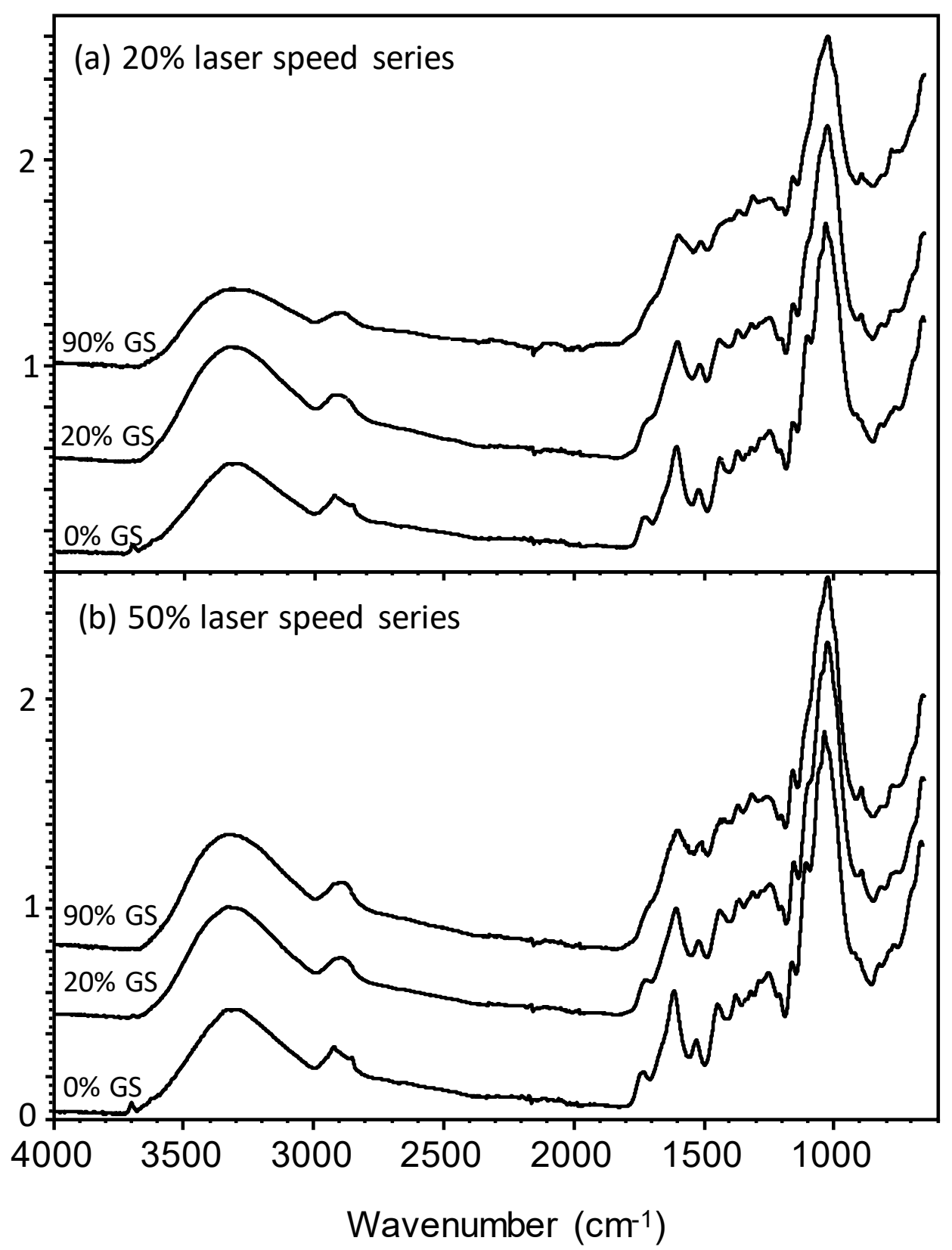

Figure 12. Stacked ATR-FTIR spectra for bark cloth laser treated samples at (a) $20 \%$ and (b) $50 \%$ laser speed. (Note the level of damage at $20 \%$ laser speed is higher due to greater overall energy input).

ATR-FTIR spectra of the pristine and laser patterned bark cloth are shown in Figure 12. The spectra show similarity to wood, the C-O stretching region $\left(1200-850 \mathrm{~cm}^{-1}\right)$ (Emmanuel et al., 2015) can be assigned to the cellulose polymer structure and peaks in the range 1780 $1480 \mathrm{~cm}^{-1}$ may be assigned to lignin (Emmanuel et al., 2015). The hydrogen bonded O-H stretching band envelope of the bark cloth does not show clear contributions from specific hydrogen bonds that are seen in the cotton cellulose crystal structure. This indicates there is a somewhat reduced amount of crystalline cellulose polymer in the bark cloth and possibly a greater contribution from water that may act to obscure such bands. Considering the origin of 
the cloth, it is perfectly reasonable for it to have an IR spectrum similar to that of wood. However, in the bark cloth, a sharp, but weak non-hydrogen bonded $\mathrm{OH}$ stretching vibration at $3700 \mathrm{~cm}^{-1}$ is evident, this is most likely due to an inorganic material such as a metal hydroxide. The EDX data (Figure 7) indicates presence of calcium and magnesium; hydroxides of these metals have $\mathrm{OH}$ stretching bands at $3642 \mathrm{~cm}^{-1}$ and $3490 \mathrm{~cm}^{-1}$, respectively. Therefore, the peak at $3700 \mathrm{~cm}^{-1}$ in the bark cloth cannot be assigned to these hydroxides. Plant material such as grasses are known to contain silicon in the form of silica (Brewer et al., 2009); OH stretching of isolated silanol groups falls in the range $3700 \mathrm{~cm}^{-1}$, the EDX data, however shows no silicon (at ca. $1.75 \mathrm{keV}$ ), though there is some broad band noise in the spectrum which may hide a small silicon peak.

During laser etching the lignin structure is damaged resulting in red-shifting of the carbonyl vibration at $1725 \mathrm{~cm}^{-1}$ to ca. $1700 \mathrm{~cm}^{-1}$, such that it begins to merge with the $\mathrm{C}=\mathrm{C}$ bands at $1600 \mathrm{~cm}^{-1}$, these changes may be due to the formation of $\alpha \beta$-unsaturated carbonyl compounds as a result of oxidation. The latter together with the aromatic structures may lead to chromophoric behaviour, thereby giving the darkening of colour. It is also evident that an additional carbonyl peak may be emerging at about $1775 \mathrm{~cm}^{-1}$. The $\mathrm{C}=\mathrm{C}$ stretching bands at $1600 \mathrm{~cm}^{-1}$ and the aromatic $\mathrm{C}=\mathrm{C}$ deformation at $1540 \mathrm{~cm}^{-1}$ are largely unaffected. The latter structures are relatively stable. FTIR analysis of the charring process of wood had been published in the context of biochar formation (Rutherford et al., 2012); comparison with the laser treated bark cloth reveals some similarities in behaviour though the changes in the bark cloth spectra are rather more subtle.

The C-O stretching bands of the cellulose component become broader and hence much less defined such that the peaks tended to merge together. These changes are entirely consistent with the SEM observations, which show damage similar to that seen in a research on laser patterning of denim (Venkatraman and Liauw, 2019). Interestingly in wood charring studies the cellulose $\mathrm{C}-\mathrm{O}$ peaks are not affected at low levels of charring though the temperature reached on exposure to the laser was substantially higher than the $250^{\circ} \mathrm{C}$ in the study by Rutherford et al., (2012).

The non-H-bonded inorganic $\mathrm{OH}$ species reduced in intensity at 50\% laser speed and 20\% grayscale and was eliminated completely on reducing the laser speed to $20 \%$ and keeping grayscale at $20 \%$. As this $\mathrm{OH}$ band was most probably from silica, it was somewhat unexpected that it did not remain in the material after laser treatment, this may be due to dehydration or if the particles are very fine, they could be removed together with carbon/ash (smoke) particles during laser etching.

At 50\% laser speed the same changes are apparent but to a lesser degree due to the reduced energy input resulting from the faster moving laser beam.

\section{Garment specification and construction}

A female jacket/top - size 12 was constructed to determine the clothing fit (Figure 13a). Lockstitch was used for hem and twin needle seams were used to join front and back panels. The bark cloth was fused with a knitted fusible interfacing to offer desired drape, fit and apply 
prints. The garment was fitted on to a size 12 female mannequin to determine the fit [point of measure of the garment was - chest $36 \mathrm{~cm}$; waist $45 \mathrm{~cm}$; shoulder $36 \mathrm{~cm}$; sleeve length $57 \mathrm{~cm}$ and body length $62.5 \mathrm{~cm}$ ]. The garment offered satisfactory shape and handle, and it was easy to don and doff the garment from the mannequin. Sublimation printing trials revealed that print designs were transferred instantly using a heat transfer machine. Three different feed speeds were tested - feed speed 4.0,6.0 and 8.0. There was no print dye penetration at the reverse side of the fabric for all the trials. However, there were minor differences in quality of print designs when fed at speed 4 and 6 as illustrated below (Figure 14). The sublimation prints were tested without fusing with the interfacing.

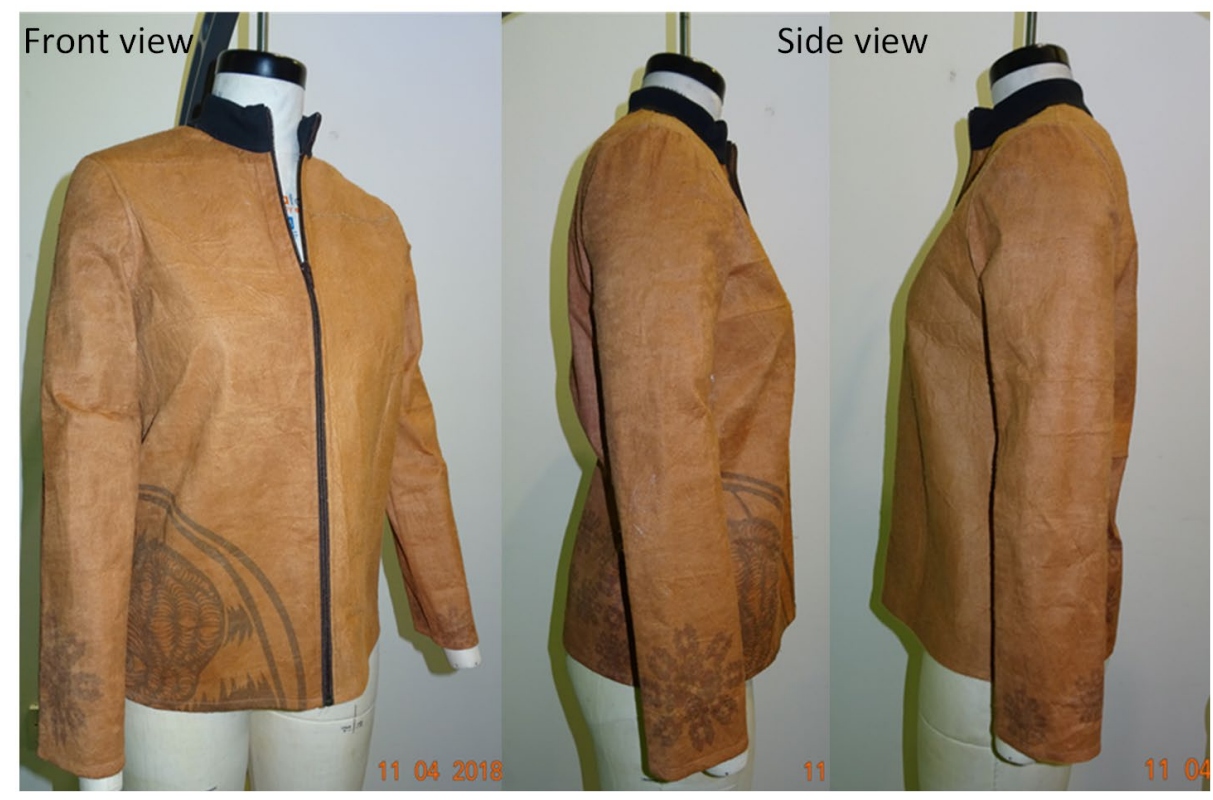

Figure 13. (a) Bark cloth on a mannequin

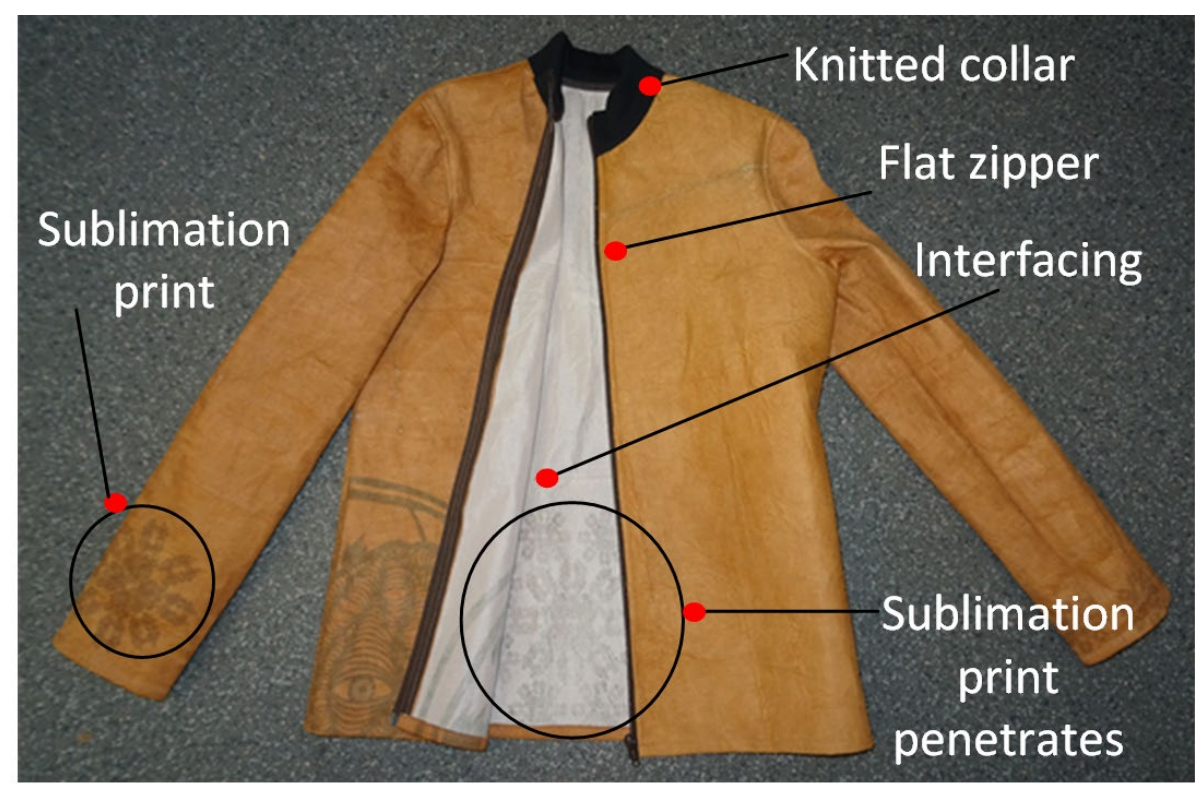

Figure 13. (b) A sample garment designed using bark cloth 


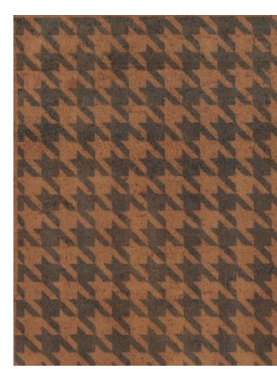

Houndstooth design

A- Sublimation print feed speed $4.0(1.16 \mathrm{~cm} / \mathrm{sec})$

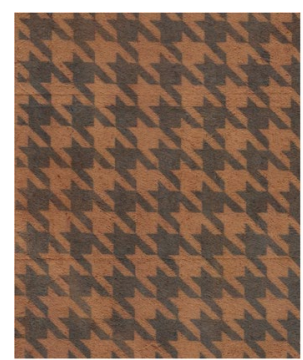

Houndstooth design

B- Sublimation print feed speed $6.0(1.66 \mathrm{~cm} / \mathrm{sec})$

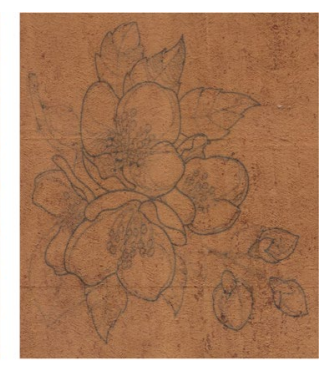

Floral design

$66 \mathrm{~cm} / \mathrm{sec}$

Figure 14. Sublimation printed bark cloth

\section{Aesthetic experimentation}

To better understand the aesthetic potential of bark cloth, an open-ended, process-led research approach was adopted that used both traditional and non-traditional crafting techniques. The bark cloth was investigated to discover the potential to add value, refinement and to adapt the surface of the cloth, while maintaining the qualities required in garment making, such as flexibility, strength, durability and comfort. A series of samples were made to determine ways in which it might be treated to offer a more sophisticated effect. Treatments included embroidery, print, appliqué, gilding, laser cutting and natural dyes. Table 2 outlines the results of this first round of sampling.

Table 2 Decorative surface treatments of bark cloth

\begin{tabular}{|c|c|c|c|}
\hline Treatment & Techniques & Results & Recommendations \\
\hline Embroidery & $\begin{array}{l}\text { Gold work } \\
\text { Black work } \\
\text { Cut work } \\
\text { Motifs } \\
\text { Top stitching } \\
\text { Blanket stitch }\end{array}$ & $\begin{array}{l}\text { No obvious limitations to } \\
\text { these techniques for bark } \\
\text { cloth. All approaches tried so } \\
\text { far have worked well. } \\
\text { Can add structural support to } \\
\text { the cloth. } \\
\text { Time consuming. }\end{array}$ & $\begin{array}{l}\text { Very adaptable to } \\
\text { individual aesthetic } \\
\text { demand. } \\
\text { Some approaches/ } \\
\text { stitches/motifs convey } \\
\text { modernity better than } \\
\text { others at this point in time. } \\
\text { Lots of potential for further } \\
\text { development. }\end{array}$ \\
\hline Patching & $\begin{array}{l}5 \mathrm{~cm} \times 5 \mathrm{~cm} \\
\text { Random }\end{array}$ & $\begin{array}{l}\text { The technique can add value } \\
\text { to the cloth and provides } \\
\text { structural support. } \\
\text { Time consuming. }\end{array}$ & $\begin{array}{l}\text { While this technique } \\
\text { strengthens the bark cloth, } \\
\text { it also has potential in } \\
\text { seamless shape making. }\end{array}$ \\
\hline Print & $\begin{array}{l}\text { Ink Jet } \\
\text { Sublimation }\end{array}$ & $\begin{array}{l}\text { Both techniques have worked } \\
\text { well on small samples of } \\
\text { bark cloth. }\end{array}$ & $\begin{array}{l}\text { Larger scale tests are } \\
\text { needed to better establish } \\
\text { potential. }\end{array}$ \\
\hline Appliqué & $\begin{array}{l}\text { Using: } \\
\text { Bark cloth } \\
\text { Beads }\end{array}$ & $\begin{array}{l}\text { Successful initial } \\
\text { experiments that ranged from } \\
\text { quite traditional to more } \\
\text { contemporary approaches. } \\
\text { Time consuming. }\end{array}$ & $\begin{array}{l}\text { Lots of potential to add } \\
\text { aesthetic value to bark } \\
\text { cloth with these techniques. }\end{array}$ \\
\hline
\end{tabular}




\begin{tabular}{clll}
\hline Gilding & Geflective fabric & & \\
\hline Fusing & With cork & $\begin{array}{l}\text { Effective treatment of the } \\
\text { surface, adding strength and } \\
\text { lustre. Obscures the natural } \\
\text { aesthetic of bark cloth and } \\
\text { gives a smoother finish. }\end{array}$ & $\begin{array}{l}\text { Works well for certain } \\
\text { projects. Potential for } \\
\text { further exploration. }\end{array}$ \\
\hline Laser cutting & $\begin{array}{l}\text { Adds strength to the bark } \\
\text { cloth and gives leather-like } \\
\text { properties. }\end{array}$ & $\begin{array}{l}\text { Limits the flexibility of } \\
\text { bark cloth - best used for } \\
\text { smaller items, accessories } \\
\text { etc. Potential for further } \\
\text { exploration. }\end{array}$ \\
\hline & cork & $\begin{array}{l}\text { Strong contemporary finish. } \\
\text { Cutting out a lot of material } \\
\text { limits the strength of bark } \\
\text { cloth, even when fused. }\end{array}$ & $\begin{array}{l}\text { Best used for smaller } \\
\text { items, accessories etc. and } \\
\text { mounted on another fabric. }\end{array}$ \\
\hline
\end{tabular}

In addition, some natural dye tests were carried out to determine the effectiveness of indigo and logwood on bark cloth (Figure 15 and 16). While bark cloth has potential as a sustainable fashion textile, its natural rust colour and rough surface carry connotations of rural handicraft and therefore limits its versatility. This natural colour may be lifted with bleach, but early tests suggested that this would eat away the fibres leaving a much more delicate material.

Tests with dyeing small pieces of bark cloth with indigo proved successful in achieving a black shade, with double dipping and washing with cold water (Figure 15). However, large sheets of bark cloth immersed in an indigo dye vat had limited success: the high absorption rate of bark cloth made it quickly become saturated and heavy, leading to some tears in the cloth as it was lifted. The colour obtained was a dark blue rather than black. Further testing is needed to resolve this. Tests with a logwood 'paint' achieved a good black shade.

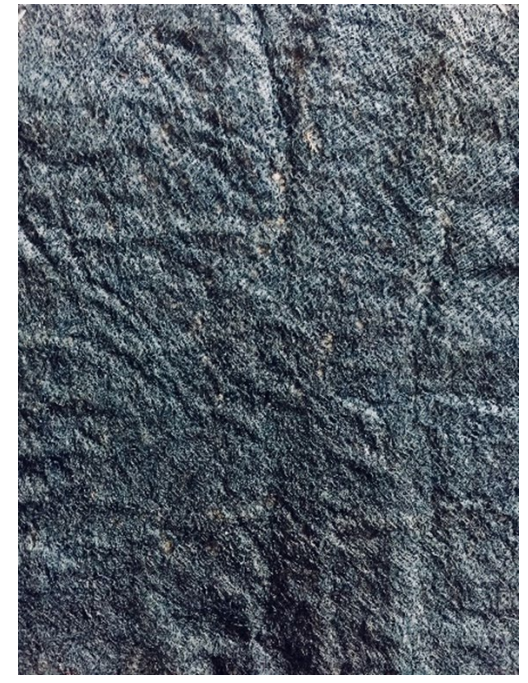

Figure 15. Indigo dyed bark cloth

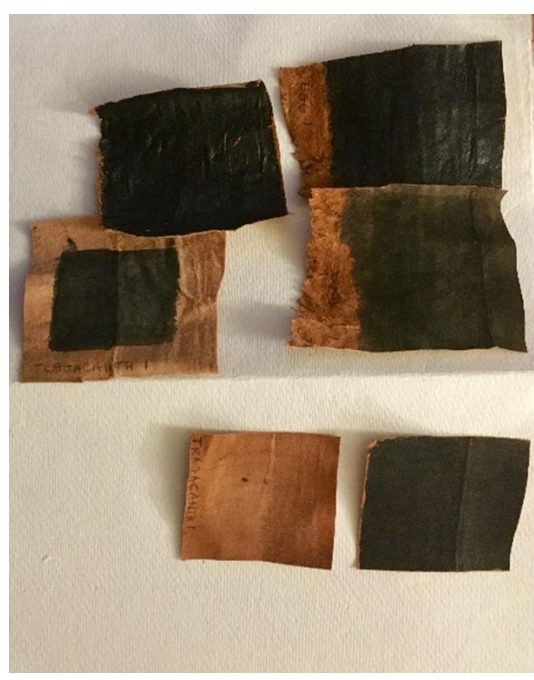

Figure 16. Logwood dye experiments

Tests have shown that bark cloth is quite versatile in creating different decorative, surface effects, that it does not fray and absorbs dye well. The research to date suggests 
that bark cloth has a lot of potential as a sustainable luxury material that may be sourced directly from the makers for small scale and eco-fashion design initiatives.

\section{Conclusions}

This study had highlighted the need for bark cloth to be fused with interfacing to facilitate good garment fit. A number of physical parameters were evaluated for bark cloth and with interfacing including thickness, strength, stiffness, and fabric drape. The raw bark cloth had variations in thickness, texture and density. To counteract these structural variations, facilitate fabric handle, garment making and to incorporate print designs and laser etching, the bark cloth was fused with a suitable interfacing. Our results show that the tensile strength of bark cloth, as well as its fabric handle, can be enhanced using light or heavy weight cotton fusible interfacing.

Fabric was etched with laser to incorporate surface designs and sublimation print was also carried out. Scanning electron microscopy revealed that laser etching occurred only on the surface of the bark cloth without affecting its structure. This was noted at $20 \%$ gray scale and 20\% laser speed. Optimal laser parameters were identified - 500 PPI, 20\% GS, 20\% laser speed and $5 \%$ laser power that could allow surface designs following fusing with a medium weight knitted interfacing. ATR-FTIR of unetched and laser etched bark cloth revealed that the lignin component underwent structural modification which most probably resulted in darkening (a precursor to charring) of the material colour. The cellulose component also lost some structural definition in much the same way as laser etched cotton cellulose. Sublimation print revealed that print dyes did not penetrated the surface of the fabric; hence, by varying the fabric feed speed the print quality could be optimised.

Figure $13 \mathrm{~b}$ revealed that the garment made out of bark cloth fused with knitted fusible interfacing offered good fit and shape. Bark cloth has the potential to be used as a sustainable fashion textile, but in its natural condition has a very specific and limited look. In order to effectively propose bark cloth for use in the sustainable fashion market, an initial exploration took place to determine the ways in which it might be treated to offer more diverse and luxurious effects.

Previous research had evaluated the suitability of bark cloth for technical applications such as body panels for cars (Rwawiire et al, 2015), comfort next to the skin and thermo-physiological properties (Rwawiire and Tomkova, 2014). Our study highlights the potential use of bark cloth for fashion garments when fused with an appropriate interfacing and surface treatment [laser etching/patterning and sublimation printing]. The natural variations of bark cloth are largely eliminated by interfacing which reinforces the structure and facilitates garment making. This research adds new information to the literature: previous research did not attempt to focus on garment shaping and draping with bark cloth, following surface treatment.

This research will inspire methods for producing apparel from sustainable materials such as bark cloth that feature desirable garment properties and may indirectly create demand for bark cloth from Uganda, thus helping to support the artisans involved in the production of sustainable bark cloth. The research can be applied to develop surface patterns using laser, 
sublimation print, embroidery and natural dyeing strategies, so that interesting designs and textures could be produced which influence designers and clothing professionals' choices when using bark cloth for the luxury market. The outcomes from this research will benefit the Ugandan community making bark cloth, local designers; Higher education [HE] in academic practice, UK and clothing designers-makers in producing luxury crafts and garments using this sustainable material.

\section{Further work}

Based on the current investigation, it is proposed that the research will develop further garments to determine the effect of interfacing on garment performance including drape, user comfort, garment aesthetics, fit, and tactile sensation, using wearer trials. In addition, it will be important to ensure that any interfacings used in future are environmentally sustainable. There is also potential to treat bark cloth with biopolymers to improve its texture, strength and fabric handle, which will facilitate garment making process and consumer care.

The current project exploring the potential of craft-based bark cloth garments is at its early stage. Consideration of user perspectives is essential to understand the potential of their response to wearing it, and their awareness of bark cloth's origin. In addition, there are less immediately tangible qualities to bark cloth that may contribute to the health and wellbeing of its wearers, such as its anti-bacterial properties, mosquito repellence, and a connection to nature transmitted by a relatively unmediated, tree-derived textile. This is an interesting aspect of the bark cloth research, which will be reported in detail in subsequent stages.

\section{Limitations}

During this research, bark cloth was limited in quantity, hence only two garments were made, however, during the next stages, a suitable quantity of bark cloth will be sourced, tested, and its relevance to apparel applications will be examined.

\section{Acknowledgements}

Authors would like to acknowledge the kind contribution of bark cloth for analysis, technician James Roscoe for laser engraving, Jayne Gill technical team leader for garment making and sublimation print designs at Manchester Fashion Institute. Hayley Andrews for Scanning Electron Microscope analysis and the contributions Karen Spurgin in the aesthetic explorations. Kirsten Scott for providing pictures from their fieldwork in Uganda and Lesli Robertson for providing pictures of bark cloth artwork.

\section{Funding}

Authors would like to thank the research cluster for funding the research and part of the work was disseminated in the $91^{\text {st }}$ Textile Institute World Conference, Leeds, U.K (Venkatraman and Scott, 2018).

\section{References}


1. Adams, K., (2015), Tree bark transforms into fashion in Uganda, The market place, https://www.marketplace.org/2015/09/09/world/tree-bark-transforms-fashion-uganda, [Accessed 12.03.2018]

2. Brewer, C., Schmidt-Rohr, K., Satrio, J. and Brown, R. (2009) 'Characterization of biochar from fast pyrolysis and gasification systems'. Environmental Progress \& Sustainable Energy, 28(3) pp.386-396. https://doi.org/10.1002/ep.10378

3. BS 5058 (1973) Method for the assessment of drape of fabrics, Milton Keynes: BSI, accessed online 21.03.2017

4. BS 9073-7 (1998) Textiles: Test methods for nonwovens - Determination of bending length, Milton Keynes: BSI, accessed online 21.03.2017

5. BS EN 13937-3 (2000) Textiles - Tear properties of fabrics- part 3: Determination of tear force of wing-shaped test specimens. Milton Keynes: BSI, accessed online 21.03.2017

6. BS EN ISO 13934-1 (2013) Tensile properties of fabrics. Determination of maximum force and elongation using strip method, Milton Keynes: British standards Institution, BSI, accessed online 24.03.2017

7. BS EN ISO 13938-2: (1999) Bursting properties of fabrics. Pneumatic method for determination of bursting strength and bursting distension, Milton Keynes: BSI, accessed online 21.03.2017

8. BS EN ISO 5084 (1987) Textiles. Determination of thickness of textiles and textile products, Milton Keynes: British standards Institution, BSI, accessed online 24.03.2017

9. Collier, B.J., Paulins V.A. and Collier, J.R., (1989) Effect of interfacing type on shear and drape behaviour of apparel fabrics, Clothing and Textiles Research Journal, 7 (3), 51-56.

10. Coombe, R. (1993) 'The Properties of Culture and the Politics of Possessing Identity: Native Claims in the Cultural Appropriation Controversy' in Canadian Journal of Law and Jurisprudence, 6:2, July 1993, pp 249-285

11. De Smet, D., Weydts D and Vanestte M., (2015) Environmentally friendly fabric finishes, In: Sustainable Apparel: production, processing and recycling, Eds. Blackburn R., Cambridge: Woodhead publishing, pp-3-33 http://dx.doi.org/10.1016/B978-1-78242-339-3.00001-7

12. Debonath, S., (2015) Sustainable production of bast fibres, Sustainable fibres and textiles, Elsevier Ltd. pp- 69-85 http://dx.doi.org/10.1016/B978-0-08-102041-8.00003-2

13. Elkington, J. (1994). Towards the sustainable corporation: Win-win-win business strategies for sustainable development. California Management Review, 36(2), 90-100. https://doi.org/10.2307/41165746

14. Emmanuel, V., Odile, B. and Céline, R. (2015) 'FTIR spectroscopy of woods: A new approach to study the weathering of the carving face of a sculpture'. Spectrochimica Acta Part A: Molecular and Biomolecular Spectroscopy, 136 pp.1255-1259, https://doi.org/10.1016/j.saa.2014.10.011

15. Fletcher, K. (2008), Sustainable Fashion and Textiles, Design Journeys, London: Earthscan.

16. Gwilt, A. (2014) A practical guide to sustainable fashion. 1st ed. London: Bloomsbury Publishing PLC.

17. Higg Index (2019), Higg Materials Sustainability Index, Sustainable Coalition Apparel, https://msi.higg.org/page/msi-home [Accessed 12.09. 2019]

18. Koenig, S.K. and Kadolph, S.J., (1983), Comparison of performance characteristics of seven fusible interfacings, Textile Research Journal, 53, 341-46.

19. Mazzarella F., Mitchell, V., and Escobar-Tello, C. (2017) Crafting Sustainable Futures. The Value of the Service Designer in Activating Meaningful Social Innovation from within Textile Artisan Communities, The Design Journal, 20:sup1, S2935-S2950, https://doi.org/10.1080/14606925.2017.1352803 
20. Musinguzi B., (2005) Uganda: Unesco Honours Uganda's Art of Bark Cloth Making, The East African, http://allafrica.com/stories/200512300282.html

21. Muthu S.S., (ed.) (2019) Circular economy in Textiles and Apparel - Processing, Manufacturing, and Design, Duxford: Woodhead publishing, https://doi.org/10.1016/B978-0-08-102630-4.01002$\underline{5}$

22. Nagano, S., (1985). Proper evaluation of and quality design of garment interfacing, In S. Kawabata, R. Postle and M Niwa (Eds). Objective measurement: Applications to product design and control (pp-235-42), Osaka: The Textile Machinery Society of Japan

23. Nakazibwe, V. (2005) Barkcloth of the Baganda People of Southern Uganda: A Record of Continuity and Change from the late $20^{\text {th }}$ Century to the early $21^{\text {st }}$ Century, Doctoral Thesis, Middlesex University, available from: http://ethos.bl.uk/SearchResults.do [accessed 19.02.17)

24. Niinimäki, K. and Hassi, L. (2011), Emerging design strategies in sustainable production and consumption of textiles and clothing, Journal of Cleaner Production, 19(2011) 1876-83.

25. Parker, L. (2016) Fashion brands and workers' rights, In: Fletcher K., and Tham, M. (2014) Routledge Handbook of Sustainability and Fashion, $1^{\text {st }}$ Edn. London: Routledge.

26. Pulse of the fashion industry (2017), Global Fashion Agenda and The Boston Consulting Group, Inc. https://globalfashionagenda.com/wp-content/uploads/2017/05/Pulse-of-the-FashionIndustry 2017.pdf

27. Resta, B. and Dotti, S. (2015) 'Environmental impact assessment methods for textiles and clothing'. Handbook of Life Cycle Assessment (LCA) of Textiles and Clothing, pp.149-191 https://dx.doi.org/10.1016/b978-0-08-100169-1.00008-3

28. Robertson, L., (2014) 'Rethinking Material Culture: Ugandan Bark Cloth', published in Textile Society of America 2014 Biennial Symposium Proceedings: New Directions: Examining the Past, Creating the Future, Los Angeles, California, September 10-14, 2014, http://digitalcommons.unl.edu/tsaconf/897/

29. Rutherford, D., Wershaw, R., Rostad, C. and Kelly, C. (2012) 'Effect of formation conditions on biochars: Compositional and structural properties of cellulose, lignin, and pine biochars'. Biomass and Bioenergy, 46 pp.693-701.http://dx.doi.org/10.1016/j.biombioe.2012.06.026

30. Rwawiire, S. and Tomkova, B., (2014) Thermo-physiological and comfort properties of Ugandan barkcloth from Ficus natalensis, The Journal of the Textile Institute, 105:6, 648-653, http://dx.doi.org/10.1080/00405000.2013.843849

31. Rwawiire, S., Catherine, N., Baker, K.S. and Davis, G., (2012) Processing of natural fiber textile from Ficus natalensis and Antiaris toxicaria, In: Proceedings of the 2nd International Symposium on sustainable development through research in natural textile fibers, textile products and marketing, Kisumu, Kenya.

32. Rwawiire, S., Luggya, G.W. and Tomkova B., (2013) Morphology, thermal and mechanical characterisation of bark cloth from Ficus natalensis, ISRN Textiles, Hindawi Publishing Co.Vol. 2013.

33. Šajn N., (2019) Environmental impact of the textile and clothing industry - what consumers need to know, European parliamentary research service. EU. PE633.143

34. Saville, B.P., (1999) Physical testing of textiles, Oxford: Woodhead publishing Ltd.

35. Scott K. (2019) A recent trip to Uganda and discussions with makers of bark cloth, Unpublished work, Aug 2019.

36. Stabler (2019), Fusible Interfacing, The Mill, John Stabler Textiles Ltd., Leeds, U.K. (Email communication) www.stabler.co.uk $16^{\text {th }}$ Sep 2019

37. Süle G., (2012) Investigation of bending and drape properties of woven fabrics and the effects of fabric constructional parameters and warp tension on these properties. Textile Research journal, 82(8), 810-819, https://doi.org/10.1177/0040517511433152 
38. Taylor M.A, (1993) Technology of textile properties, $3^{\text {rd }}$ edition. Suffolk: Forbes Publication

39. Tischner, U and Charter, M. (2001) Sustainable product design. In: Charter, M. and Tischner, U. (Eds.), Sustainable solutions: Developing products and services for the future, Greenleaf, Sheffield pp.118-138

40. Trowell, M. and Waschmann, K.P., (1953) Tribal Crafts of Uganda, London: Oxford University Press

41. UNESCO (2008) A report on the revitalisation of bark cloth making in Uganda UNESCO/Japanese funds-in-trust Project

42. Venkatraman, P.D. and Liauw, C. M., (2019) 'Use of a carbon dioxide laser for environmentally beneficial generation of distressed/faded effects on indigo dyed denim fabric: Evaluation of colour change, fibre morphology, degradation and textile properties'. Optics \& Laser Technology, 111 pp.701-713. https://doi.org/10.1016/j.optlastec.2018.09.004

43. Venkatraman, P.D. and Scott, K., (2018), Investigation of bark cloth for its surface texture and durability for apparel applications, Presented at the 91st Textile Institute World Conference, University of Leeds, U.K. 23-26th July 2018.

44. WCED (1987) Our Common Future World Commission on Environment and Development, Oxford: Oxford University Press.

45. Wolf, O. Kougoulis J., Cordella M. and Dodd N., (2014) (eds) Environmental Improvement Potential of Textiles, (IMPRO) European Commission Joint Research Centre (JRC), http://ipts.jrc.ec.europa.eu/

46. Worden, S., (2016) "Tradition and Transition: The changing fortunes of barkcloth in Uganda", Textile Society of America Symposium Proceedings. 1012. $\underline{\text { http://digitalcommons.unl.edu/tsaconf/1012 }}$

47. World Fair Trade Organisation (WFTO) (2017) 10 Principles of Fair Trade, https://wfto.com/fairtrade/10-principles-fair-trade [accessed on 24.09.2019]

48. WRAP (2015), Sustainable clothing - A practical guide to enhancing clothing durability and performance, Oxon: WRAP, http://wrap.org.uk [accessed 12.09.2019]. 